\title{
DIGITAL ELEVATION MODEL FROM NON-METRIC CAMERA IN UAS COMPARED WITH LIDAR TECHNOLOGY
}

\author{
O.M. Dayamit ${ }^{a^{*}}$, M.F. Pedro ${ }^{\text {a }}$, R.R. Ernesto ${ }^{a}$, B.L. Fernando ${ }^{a}$ \\ a GEOCUBA Investigación y Consultoría, Loma y 39, Municipio Plaza de la Revolución, La Habana, Cuba - (dayamit, pedrom, \\ erroche, bravo)@uct.geocuba.cu
}

Commission I, Working Group I/Vb

KEY WORDS: Surveying, UAS, LIDAR, DEM/DTM, Accuracy

\begin{abstract}
:
Digital Elevation Model (DEM) data as a representation of surface topography is highly demanded for use in spatial analysis and modelling. Aimed to that issue many methods of acquisition data and process it are developed, from traditional surveying until modern technology like LIDAR. On the other hands, in a past four year the development of Unamend Aerial System (UAS) aimed to Geomatic bring us the possibility to acquire data about surface by non-metric digital camera on board in a short time with good quality for some analysis. Data collectors have attracted tremendous attention on UAS due to possibility of the determination of volume changes over time, monitoring of the breakwaters, hydrological modelling including flood simulation, drainage networks, among others whose support in DEM for proper analysis. The DEM quality is considered as a combination of DEM accuracy and DEM suitability so; this paper is aimed to analyse the quality of the DEM from non-metric digital camera on UAS compared with a DEM from LIDAR corresponding to same geographic space covering $4 \mathrm{~km}^{2}$ in Artemisa province, Cuba. This area is in a frame of urban planning whose need to know the topographic characteristics in order to analyse hydrology behaviour and decide the best place for make roads, building and so on. Base on LIDAR technology is still more accurate method, it offer us a pattern for test DEM from non-metric digital camera on UAS, whose are much more flexible and bring a solution for many applications whose needs DEM of detail.
\end{abstract}

\section{INTRODUCTION}

Nowadays exist an increasing demand of Digital Elevation Model (DEM) data as a representation of surface topography for use in spatial analysis and modelling to support many political and environmental stakeholders. The DEM quality involves factors such as terrain morphology, input data acquisition, and interpolation method. In addition, the DEM quality is consider as a combination of DEM accuracy and DEM suitability. While DEM accuracy refers to the fact how representative the DEM is compared to the real landscape, DEM suitability refers to how suitable the DEM is for certain application or model (Bonk, 2007). Aimed to that issue many methods of acquisition data and process it are developed, from traditional surveying until modern technology like LIDAR; but even with these methods of data capture a lot of work still needs to be done in processing, refining and adapting the data for specific purpose. In a past four year the development of Unamend Aerial System aimed to Geomatic bring us the possibility to acquire data about surface topography by nonmetric digital camera on board in short time with good quality for spatial analysis and environmental modelling. Nevertheless, how this data are good enough and for whish propose it can be used is an interesting task to research.

The acceptance of Unmanned Aerial System (UAS) for a multitude of applications is on the rise in many countries. In the wake of these developments, UAS is also rapidly becoming a tool for surveyors. However, UAS surveys do not directly produce vector data, the analysis and digitalization is conducted in the office using DEM. Virtual surveying is done in 3D model, which resembles the terrain and the surveyor can navigate through the model and measure point by clicking the mouse. (Op 't Eyndt \& Volkmann, 2013). Most of UAS systems build their DEM from pairs of no metric photographs base in correlation. Once a set of images has been oriented, and the exterior orientation and camera calibration parameters have known, a scene can be digitally reconstructed by means of automated dense image matching techniques. This produce a dense point cloud describing the surface in a DEM, which has to be interpolated and simplified (Remondino et al., 2011). The quality of the DEM generation depends on several factors such as overlapping, flight altitude, camera resolution, etc. Variations in these parameters affect the final accuracy of the model obtained (Haala et al., 2011; Ruiz et al., 2013).

Because it is a relatively simple process, characterized by a high level of automation, data collectors have attracted tremendous attention on UAS due to possibility of the determination of volume changes over time, monitoring of the breakwaters, hydrological modelling including flood simulation, drainage networks, among others whose support in DEM for proper analysis. UAS also offer low costs and high flexibility of time and date of data capturing and thus enabling high temporal resolution and the spatial resolution is high. Although, the extent of the area covered by UAS is limited to the autonomy of the aircraft (Ojeda Martínez et al., 2014).

Moreover, the DEM obtained from Light Detection and Ranging (LIDAR) technology offers a number of significant advantages emphasizing in accuracy. LIDAR technology provides high-resolution point clouds of the topography and has several applications for mapping. A Global Positioning System (GPS) defines the absolute position of the sensor, and its attitude is recorded by an inertial system. The point cloud coordinates are estimated with an accuracy of around $15 \mathrm{~cm}$ (Jaboyedoff et al., 2012). The benefits can be an outcome of differing efficiencies arising from either the sampling design and/or the estimation method. In both cases, efficiencies are gained when there is a strong relationship between the variable of interest and the derived LiDAR metrics (Melville et al., 2015). Extract the most precise information possible using the 
smallest number of plots is the key for cost-benefice valance with this technology.

This paper presents a comparative analysis between two DEM. They were created in the same geographical area, corresponding to a sector with partially rough surfaces of Artemisa province. One model was done with airborne-based LIDAR, and the second DEM was base in a colour photos obtained with a no metric camera of 16 megapixel installed on a UAV. For both cases were define accuracy, which allows used these MDE in certain activities of the economy.

\section{METHODOLOGY}

\subsection{Study area}

The study area corresponds to $4 \mathrm{~km}^{2}$ of Artemisa province. Relieve is partially rough, gets to reach slopes of up to $16^{\circ}$. Minimum elevation is $0 \mathrm{~m}$ and maximum elevation is $55 \mathrm{~m}$. This area is in a frame of urban planning, for that reason topography study is needed in order to analyse the behaviour of hydrology, also for project and construct architecture. Some hydrological even like flooding cannot be completely avoided, but damages from severe events can be reduced if effective flood prevention steps are implemented where DEM is an important piece (Adolf Szabó, 2007).

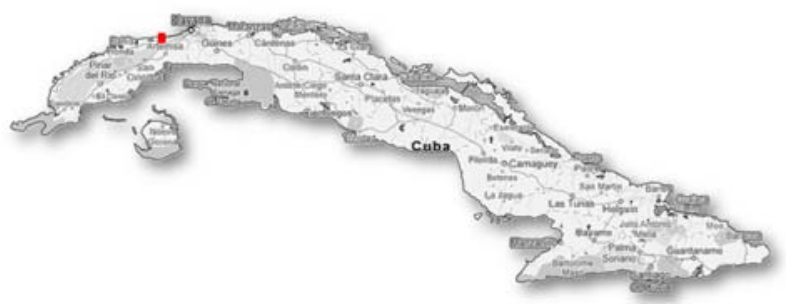

Figure 1. Location of study area in square red

\subsection{Data acquisition process}

The first DEM was developed from UAS survey with DeltaPhoto system on July 10, 2014. The aircraft weights $5 \mathrm{~kg}$ and is equipped with GPS/IMU and steered from a ground control station (GCS) for flight planning and controlling. PhotoScan Pro, a photogrammetric software package for desktop computer accompanies this system aimed to process the resulting image. The flight duration of the aircraft was 45 minute and the cruise speed was $70 \mathrm{~km} / \mathrm{h}$. The non-metric digital camera on board is a 16 megapixels SONY NEX-5N with focal length equal to 20 $\mathrm{mm}$, which gives us a ground sampling distance (GSD) of $5 \mathrm{~cm}$ at an altitude of $200 \mathrm{~m}$. The pilot site was an area of $4 \mathrm{~km}^{2}$, and the number of images required to cover the area was 1446. All images were processed and result was three geo-referenced products, 3D models, orthoimagery and DEM. The last one was computed based on grid of regularly spaced discrete data points and exported to $20 \mathrm{~cm}$.

The second DEM was developed from airborne LIDAR survey with GIEGL LMS-Q120 system on November 01, 2014. The scanner mechanism is rotating polygon mirror, with scan frequency between 5 to $100 \mathrm{scan} / \mathrm{sec}$, scan angel equal to 80 degree and it is equipped with GPS and GLONASS, the accuracy in post-processed can by $2 \mathrm{~cm}$ in $\mathrm{Z}$ and $5 \mathrm{~cm}$ in $\mathrm{XY}$ for each point according to producer. The point density was 6 per square meter. The pilot site was an area of $35 \mathrm{~km}^{2}$, however for this experiment only was used $4 \mathrm{~km}^{2}$ corresponding to UAS survey.

\subsection{Accuracy Analysis}

DEM is considering 'good' if it represents the topographic surface accurately. Grid DEM obtained from TIN-interpolated random points of orthophoto heights can display systematic errors in the form of planar triangle facets at sparsely located control points, typically in flat terrains. Such areas should be either excluded from curvature or locally re-interpolated with smoother surfaces. LIDAR heights data can display systematic error as sudden slope-breaks at the edges of forested or built-up areas thus biasing gradient estimation (Jordan, 2007). In this case, for tested the accuracy both DEM, 13 point of ground true was used. The $\mathrm{Z}$ value was read on every location of this point over DEM, and the Root Mean Squared Error (RMSE) was calculated. The result is show in Table 1.

\begin{tabular}{|c|c|c|c|}
\hline Point & Data & $Z(\mathbf{m})$ & $\Delta \mathrm{Z}(\mathrm{m})$ \\
\hline \multirow[t]{3}{*}{1.} & DEM UAS & 43.88 & $-0.48^{1}$ \\
\hline & DEM Lidar & 44.55 & $0.19^{2}$ \\
\hline & Ground True & \multicolumn{2}{|c|}{44.36} \\
\hline \multirow[t]{3}{*}{2.} & DEM UAS & 19.13 & 0.62 \\
\hline & DEM Lidar & 18.31 & -0.2 \\
\hline & Ground True & \multicolumn{2}{|c|}{18.51} \\
\hline \multirow[t]{3}{*}{3.} & DEM UAS & 6.84 & -0.21 \\
\hline & DEM Lidar & 7.42 & 0.37 \\
\hline & Ground True & \multicolumn{2}{|c|}{7.05} \\
\hline \multirow[t]{3}{*}{4.} & DEM UAS & 16.67 & 0.72 \\
\hline & DEM Lidar & 16.32 & 0.37 \\
\hline & Ground True & \multicolumn{2}{|c|}{15.95} \\
\hline \multirow[t]{3}{*}{5.} & DEM UAS & 12.23 & -0.60 \\
\hline & DEM Lidar & 12.48 & -0.35 \\
\hline & Ground True & \multicolumn{2}{|c|}{12.83} \\
\hline \multirow[t]{3}{*}{6.} & DEM UAS & 48.33 & -0.42 \\
\hline & DEM Lidar & 48.53 & -0.22 \\
\hline & Ground True & \multicolumn{2}{|c|}{48.75} \\
\hline \multirow[t]{3}{*}{7.} & DEM UAS & 13.92 & 0.42 \\
\hline & DEM Lidar & 13.21 & -0.29 \\
\hline & Ground True & \multicolumn{2}{|c|}{13.50} \\
\hline \multirow[t]{3}{*}{8.} & DEM UAS & 1.61 & 0.43 \\
\hline & DEM Lidar & 1.32 & 0.14 \\
\hline & Ground True & \multicolumn{2}{|c|}{1.18} \\
\hline \multirow[t]{3}{*}{9.} & DEM UAS & 24.30 & -0.26 \\
\hline & DEM Lidar & 24.39 & -0.17 \\
\hline & Ground True & \multicolumn{2}{|c|}{24.56} \\
\hline \multirow[t]{3}{*}{10.} & DEM UAS & 6.45 & -0.28 \\
\hline & DEM Lidar & 6.97 & 0.24 \\
\hline & Ground True & \multicolumn{2}{|c|}{6.73} \\
\hline \multirow[t]{3}{*}{11.} & DEM UAS & 25.23 & -0.25 \\
\hline & DEM Lidar & 25.63 & 0.15 \\
\hline & Ground True & \multicolumn{2}{|c|}{25.48} \\
\hline \multirow[t]{3}{*}{12.} & DEM UAS & 12.09 & -0.12 \\
\hline & DEM Lidar & 12.10 & -0.11 \\
\hline & Ground True & \multicolumn{2}{|c|}{12.21} \\
\hline \multirow[t]{3}{*}{13.} & DEM UAS & 0.12 & -0.37 \\
\hline & DEM Lidar & 0.36 & -0.13 \\
\hline & Ground True & \multicolumn{2}{|c|}{0.49} \\
\hline
\end{tabular}

Table 1. Behaviour of $Z$ value in both DEM

Also, for both DEM were checked the number of point with height used to interpolated the surface, the distribution of this

1 (Z DEM UAS - Z Ground true)

2 (Z DEM LIDAR - Z Ground true) 
point per square meter and after that both DEM were represented in TIN. The criterias is resumed in Table 2.

\begin{tabular}{|l|c|c|}
\hline Criteria & $\begin{array}{c}\text { DEM from non- } \\
\text { metric digital } \\
\text { camera on UAS }\end{array}$ & DEM from LIDAR \\
\hline Point Density & $\begin{array}{c}120512416 \\
\text { in } 4 \mathrm{~km}^{2}\end{array}$ & $\begin{array}{c}5310756 \\
4 \mathrm{~km}^{2}\end{array}$ \\
\hline $\begin{array}{l}\text { Point } \\
\text { Distribution }\end{array}$ & $\begin{array}{c}\text { regularly spaced } \\
25 \text { per m }\end{array}$ & $\begin{array}{c}\text { irregularly spaced } \\
2 \text { per m }\end{array}$ \\
\hline Accuracy & $0.45 \mathrm{~m}$ & $0.25 \mathrm{~m}$ \\
\hline $\begin{array}{l}\text { Method used } \\
\text { for } \\
\text { representation }\end{array}$ & TIN & TIN \\
\hline
\end{tabular}

Table 2. Comparison criteria’s for DEM accuracy analysis

In visual inspection of both DEM is noted that DEM from LIDAR is smoother than DEM from non-metric digital camera on UAS, this is the result of the large number of point used in the second DEM. Also, LIDAR technology uses the full waveform of the laser signal. The full waveform of the backscattered pulse includes some information on the properties of the reflexive objects within the beam area. This allows for instance removing part of the vegetation effect which is not possible with optical sensor. Nevertheless, if the vegetation is too dense the laser beam will not reach the ground.

In case of DEM from non-metric digital camera on UAS, better result can be obtained based on grid of regularly spaced discrete data points and exported to $25 \mathrm{~cm}$ or more. Both DEM can by appreciate in Figure 2 and 3.
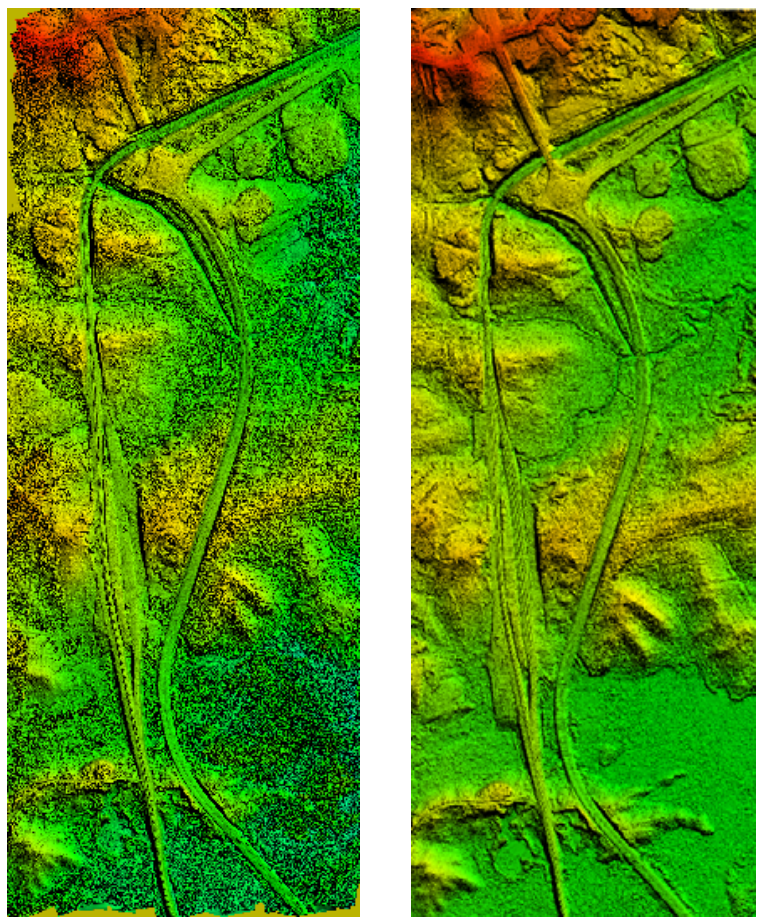

Figure 2. DEM from non-metric digital camera on UAS on left, DEM from LIDAR on right

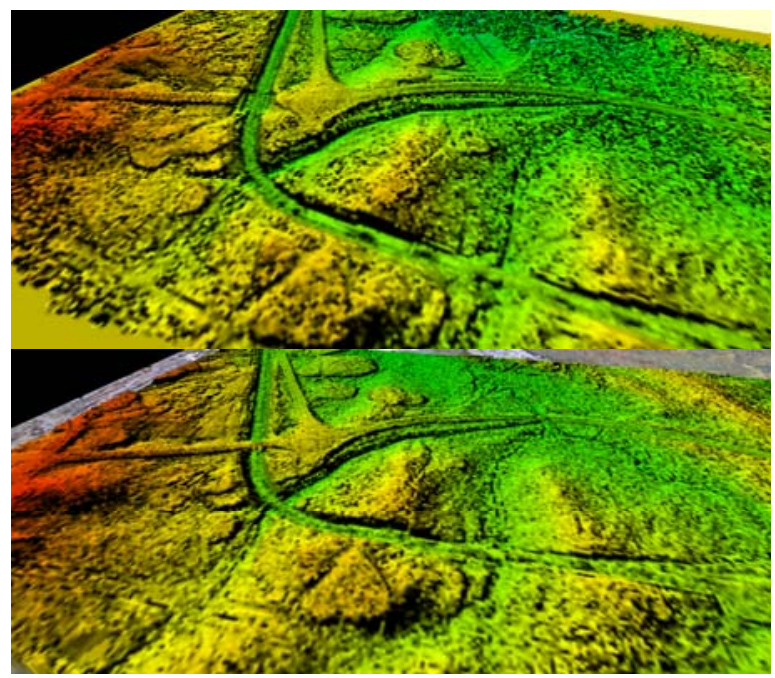

Figure 3. DEM from non-metric digital camera on UAS on top, DEM from LIDAR on bottom

\subsection{Results and discussion}

The standard resolution DEM is approximately $25 \mathrm{~m}$ grid size obtained from topographic maps. In this case DEM from nonmetric digital camera on UAS has a RMSE equal to $0.45 \mathrm{~m}$ with $0.20 \mathrm{~m}$ grid size and DEM from LIDAR has a RMSE equal to $0.25 \mathrm{~m}$. Due to absolute position of an LIDAR sensor was defined by a Global Positioning System (GPS) referred to ground control station, and its attitude is recorded by an inertial system; it has better result. The absolute position of UAS precise an additional ground point and the number of ground point defines the quality of photogrammetric process. The absolute position of UAS can be improved if applique GNSS and RTK technology paired with Ethernet support in a miniature, it power-saving design achieves centimetre to decimetre level accuracy for unmanned applications.

\section{CONCLUSIONS}

This work was oriented to evaluate the quality of the DEM from non-metric camera on UAS. DEM is obtained from TINinterpolated random points and this was compared with a DEM from LIDAR. UAS technology offers a great flexibility to quickly acquire field data in sufficient spatial resolution at low cost while LIDAR technology is still more accurate method even when stability of the plane is needed; nevertheless UAS are much more flexible and bring a solution for many applications whose needs DEM of detail. The extent of the area covered by UAS is limited due to battery autonomy; so, for large areas is necessary more than one flight. Also if high temporal resolution data is needed, DEM from aircraft-based sensor have a role for monitoring seasonally variable, example forestry and soil conditions, and for time-specific and timecritical management like landslide.

\section{REFERENCES AND SELECTED BIBLIOGRAPHY}

Adolf Szabó, J. 2007. Decision Supporting Hydrological Model for River Basin Flood Control. In R. Peckham \& G. Jordan (Eds.), Digital Terrain Modelling, pp. 145-182: Springer Berlin Heidelberg. 
Bonk, R. 2007. Scale-Dependent Effect of Input Data Design on DEM Accuracy. In R. Peckham \& G. Jordan (Eds.), Digital Terrain Modelling, pp. 83-98: Springer Berlin Heidelberg.

Haala, N., Cramer, M., Weimer, F., \& Trittler, M., 2011. Performance test on UAV-based photogrammetric data collection. Proceedings of the International Archives of the Photogrammetry, Remote Sensing and Spatial Information Sciences, 38(1/C22), 7-12.

Jaboyedoff, M., Oppikofer, T., Abellán, A., Derron, M.-H., Loye, A., Metzger, R., \& Pedrazzini, A., 2012. Use of LIDAR in landslide investigations: a review. Natural Hazards, 61(1), 528. doi: 10.1007/s11069-010-9634-2

Jordan, G. 2007. Digital Terrain Analysis in a GIS Environment. Concepts and Development. In R. Peckham \& G. Jordan (Eds.), Digital Terrain Modelling, pp. 1-43: Springer Berlin Heidelberg.

Melville, G., Stone, C., \& Turner, R., 2015. Application of LiDAR data to maximise the efficiency of inventory plots in softwood plantations. New Zealand Journal of Forestry Science, 45(1), 1-16. doi: 10.1186/s40490-015-0038-7

Ojeda Martínez, D., Fernández Sarabia, A., \& González García, S., 2014. UAS in Farming. A pilot project in Cuba GIM International. The global magazine for GEOMATICS, 28(3), 27-29.

Op 't Eyndt, T., \& Volkmann, W., 2013. UAS as a Tool for Surveyors. From tripods and trucks to virtual surveying. GIM International. The global magazine for GEOMATICS, 27(4), 20-25.

Remondino, F., Barazzetti, L., Nex, F., Scaioni, M., \& Sarazzi, D., 2011. UAV photogrammetry for mapping and 3d modelingcurrent status and future perspectives. International Archives of the Photogrammetry, Remote Sensing and Spatial Information Sciences, 38(1), C22.

Ruiz, J., Diaz-Mas, L., Perez, F., \& Viguria, A., 2013. Evaluating the accuracy of DEM generation algorithms from UAV imagery. Int. Arch. Photogramm. Remote Sens. Spatial Inf. Sci, 40, 333-337. 